OPEN ACCESS

Edited by: Erdinc Sezgin,

Karolinska Institutet (KI), Sweden

Reviewed by:

Mezida B. Saeed,

Karolinska Institutet (KI), Sweden

Huw Colin-York

University of Oxford, United Kingdom

*Correspondence:

Alessandra Cambi

alessandra.cambi@radboudumc.n

Diane S. Lidke

dlidke@salud.unm.edu

Specialty section:

This article was submitted to Molecular Innate Immunity, a section of the journal

Frontiers in Immunology

Received: 01 October 2020 Accepted: 18 December 2020 Published: 12 February 2021

Citation:

Vleeshouwers W, van den Dries K, de Keijzer S, Joosten B, Lidke DS and Cambi A (2021) Characterization of the Signaling Modalities of Prostaglandin E2 Receptors EP2 and EP4 Reveals Crosstalk and a Role for Microtubules. Front. Immunol. 11:613286. doi: 10.3389/fimmu.2020.613286

\section{Characterization of the Signaling Modalities of Prostaglandin E2 Receptors EP2 and EP4 Reveals Crosstalk and a Role for Microtubules}

\author{
Ward Vleeshouwers ${ }^{1}$, Koen van den Dries ${ }^{1}$, Sandra de Keijzer ${ }^{1}$, Ben Joosten ${ }^{1}$, \\ Diane S. Lidke ${ }^{2,3^{*}}$ and Alessandra Cambi ${ }^{1 *}$
}

\begin{abstract}
${ }^{1}$ Department of Cell Biology, Radboud Institute for Molecular Life Sciences, Radboud University Medical Center, Nijmegen, Netherlands, ${ }^{2}$ Department of Pathology, University of New Mexico Health Sciences Center, Albuquerque, NM, United States,

${ }^{3}$ Comprehensive Cancer Center, University of New Mexico Health Sciences Center, Albuquerque, NM, United States
\end{abstract}

Prostaglandin E2 (PGE2) is a lipid mediator that modulates the function of myeloid immune cells such as macrophages and dendritic cells (DCs) through the activation of the G protein-coupled receptors EP2 and EP4. While both EP2 and EP4 signaling leads to an elevation of intracellular cyclic adenosine monophosphate (cAMP) levels through the stimulating $G \alpha_{s}$ protein, EP4 also couples to the inhibitory $G \alpha_{i}$ protein to decrease the production of cAMP. The receptor-specific contributions to downstream immune modulatory functions are still poorly defined. Here, we employed quantitative imaging methods to characterize the early EP2 and EP4 signaling events in myeloid cells and their contribution to the dissolution of adhesion structures called podosomes, which is a first and essential step in DC maturation. We first show that podosome loss in DCs is primarily mediated by EP4. Next, we demonstrate that EP2 and EP4 signaling leads to distinct cAMP production profiles, with EP4 inducing a transient CAMP response and EP2 inducing a sustained CAMP response only at high PGE2 levels. We further find that simultaneous EP2 and EP4 stimulation attenuates CAMP production, suggesting a reciprocal control of EP2 and EP4 signaling. Finally, we demonstrate that efficient signaling of both EP2 and EP4 relies on an intact microtubule network. Together, these results enhance our understanding of early EP2 and EP4 signaling in myeloid cells. Considering that modulation of PGE2 signaling is regarded as an important therapeutic possibility in anti-tumor immunotherapy, our findings may facilitate the development of efficient and specific immune modulators of PGE2 receptors.

Keywords: membrane receptor, prostaglandin E2 signaling, myeloid cells, G protein-coupled receptor, podosome 


\section{INTRODUCTION}

The ability of cells to respond to their environment is critical for their function. Important players for transmitting extracellular information into intracellular signaling events are the $G$ proteincoupled receptors (GPCRs) (1). The spatiotemporal organization of GPCRs within the cell membrane allows these receptors to elicit fine-tuned cellular responses to different ligands.

Prostaglandins are lipid mediators that represent an abundant type of GPCR ligand. Prostaglandins are derived from cyclooxygenase (COX)-catalyzed metabolism of arachidonic acid and exhibit versatile actions in a wide variety of tissues (2, 3). Prostaglandin E2 (PGE2) signals via the four GPCRs EP1-4, expressed in various combinations at the plasma membrane of cells (4). PGE2 modulates several key immunological processes including the activation, migration and cytokine production of different immune cells such as dendritic cells (DCs), macrophages and $\mathrm{T}$ lymphocytes $(3,5-8)$. Despite being a known mediator of inflammation, increased PGE2 concentrations have been associated with a highly immunosuppressive tumor microenvironment (TME) of several cancer types (9-13).

DCs are commonly observed in the TME of solid tumors (14). Yet, despite their potential to generate anti-tumor immunity, TME-resident DCs often exhibit impaired or defective function (15). The high PGE2 levels in the TME might play a role in the suppression of DC phenotype since PGE2 promotes IL-10 production by DCs (16). On the other hand, by stimulating the dissolution of actin-rich adhesion structures called podosomes, PGE2 is also important for inducing the highly migratory phenotype typical of mature DCs and crucial in immunity (6). Understanding how PGE2 exerts its dual function in DCs can offer novel leads to reverse unwanted DC immunosuppression in the context of anti-tumor immunity.

PGE2 modulates DC function exclusively via EP2 and EP4 (6, 17, 18). For example, PGE2 has previously been shown to induce the dissolution of podosomes through the cAMP-PKA-RhoA signaling axis downstream of EP2 and EP4 (8). PGE2-induced podosome dissolution is an important step toward DC maturation and the acquisition of a highly migratory phenotype, but the receptor-specific contributions to these processes are still poorly defined.

Signaling via EP2 and EP4 is predominantly transduced by the stimulating $\mathrm{G} \alpha$ protein $\left(\mathrm{G \alpha}_{\mathrm{s}}\right)$, leading to increased activity of adenylate cyclase (AC) and subsequent elevation of intracellular cyclic adenosine monophosphate (cAMP) levels $(19,20)$. An important difference between EP2 and EP4 is the reported capacity of EP4 to also couple to inhibitory G $\alpha$ protein $\left(G \alpha_{i}\right)$, thereby inhibiting cAMP formation and activating a phosphatidylinositol 3-kinase (PI3K) pathway $(21,22)$. Furthermore, in contrast to EP2, EP4 is rapidly internalized upon ligand binding (23-25). Altogether, these observations suggest that signal modalities (intensity, duration, downstream effectors) likely differ between EP2 and EP4 and that a better understanding of EP2 and EP4 differential signaling is key to understanding and predicting the effects of PGE2 in DC biology.

Here, we aimed to characterize EP2 and EP4 early signaling events in response to PGE2 in myeloid cells and link them to the dissolution of podosomes in DCs. We first demonstrate that in DCs, PGE2 leads to podosome dissolution primarily through EP4 signaling. Next, we show that selective EP2 and EP4 stimulation leads to distinct cAMP production profiles and suggest reciprocal control of receptor signaling efficiency. Finally, we demonstrate that the integrity of the cortical microtubule network is important for efficient EP2 and EP4 signaling. Modulation of PGE2 signaling is considered an important therapeutic possibility in anti-tumor immunotherapy. Our findings enhance our understanding of early EP2 and EP4 signaling and may thereby facilitate the development of efficient and specific modulators of PGE2 signaling receptors that can contribute to reverse tumor immunosuppression (26).

\section{MATERIALS AND METHODS}

\section{Chemicals and Reagents}

Cells were treated with several compounds that activated or inhibited EP2 and EP4 (see database of FDA-approved compounds at www.bindingdb.org for pharmacological details): EP2 agonist (R)-Butaprost (Sigma), EP4 agonist L902688 (Cayman Chemicals), EP2 competitive antagonist AH6809 (Cayman Chemicals), EP4 competitive antagonist GW627368X (Cayman Chemicals) or AH23848 (Cayman Chemicals), pertussis toxin (TOCRIS biosciences), PGE2 (Cayman Chemicals), Pertussis Toxin (PTx, Calbiochem, San Diego, CA) and nocodazole (Sigma). Concentrations used for the various compounds are based on previous literature (27-31) in combination with viability assays (performed by Trypan Blue staining). Compounds used for immunofluorescence staining were mouse anti-vinculin antibody (Sigma, V9131), Goat antiMouse-(H\&L)-Alexa488 and Goat anti-Mouse-(H\&L)-Alexa647 secondary antibodies (Invitrogen), Alexa488-conjugated phalloidin (Invitrogen, A12379) and Texas Red-conjugated phalloidin (Invitrogen, T7471), Mowiol (Sigma).

\section{Cell Culture}

RAW 246.7 cells were cultured in RPMI-1640 medium (Gibco) supplemented with $10 \%$ Fetal Bovine Serum (FBS, Greiner Bioone), $1 \mathrm{mM}$ Ultra-glutamine (BioWitthaker) and 0.5\% AntibioticAntimytotic (AA, Gibco). iDCs were derived from PBMCs as described previously $(32,33)$ and cultured in RPMI 1640 medium (Gibco) supplied with 10\% Fetal Bovine Serum (FBS, Greiner Bioone). Transfections with t-Epac-vv (34) (gift from K. Jalink), $\mathrm{G \alpha}_{\mathrm{s}^{-}}$ GFP (gift from M. Rasenick), $\mathrm{Go}_{\mathrm{i}}$-GFP and $\mathrm{Go}_{\mathrm{il}}$-Citrine (35) (gift from A. Gilman), $G \gamma_{2}$-CFP and $G \beta_{1}$ wildtype (both gifts from $M$. Adjobo-Hermans) were performed with Fugene HD (Roche) according to the manufacturer protocol and imaged after $24 \mathrm{~h}$. Stable cell lines expressing $\mathrm{G \alpha}_{\mathrm{s}}$-GFP and $\mathrm{G}_{\mathrm{i}^{\mathrm{i}}}$-GFP was maintained using the appropriate antibiotics. Cells were plated one day prior to measurements or transfection in Willco dishes (Willco Wells BV) at 400,000 cells/dish or in 96 well-plate (microplate BD Falcon) at 40,000 cells/well or in 4-well Lab-Tek II chambered coverglass (Nunc) at 100,000 cells/chamber. Prior to imaging, the medium was replaced with $1 \mathrm{ml}$ RPMI medium without phenol red to avoid background fluorescence. 


\section{Podosome Dissolution Assay and Widefield Immunofluorescence}

For agonist experiments, iDCs were treated with (R)-Butaprost, L-902688 or $10 \mu \mathrm{M}$ PGE2 for $10 \mathrm{~min}$. For antagonist and pertussis toxin experiments, iDCs were pretreated with $3 \mu \mathrm{M}$ AH6809 for $1 \mathrm{~h}, 10 \mu \mathrm{M}$ GW627368X for $1 \mathrm{~h}, 100 \mathrm{ng} / \mathrm{ml}$ pertussis toxin for $16 \mathrm{~h}$ as previously described (22) or left untreated prior to the addition of PGE2. After stimulation, iDCs were fixed in $3.7 \%(\mathrm{w} / \mathrm{v})$ formaldehyde in PBS for $10 \mathrm{~min}$. Cells were permeabilised in $0.1 \%(\mathrm{v} / \mathrm{v})$ Triton $\mathrm{X}-100$ in PBS for $5 \mathrm{~min}$ and blocked with $2 \%(\mathrm{w} / \mathrm{v})$ BSA in PBS. The cells were incubated with mouse anti-vinculin antibody for $1 \mathrm{~h}$. Subsequently, the cells were washed with PBS and incubated with GaM-(H\&L) secondary antibody and phalloidin for $45 \mathrm{~min}$. Lastly, samples were washed with PB prior to embedding in Mowiol. Cells were imaged on a Leica DM fluorescence microscope with a $63 \times \mathrm{PL}$ APO 1.3 NA oil immersion lens and a COHU high-performance integrating CCD camera (COHU, San Diego, CA) or a Zeiss LSM 510 microscope equipped with a PlanApochromatic 63x/1.4 NA oil immersion objective. Images were analyzed using Fiji-based software (36).

\section{Förster Resonance Energy Transfer Experiments}

RAW macrophages expressing t-Epac-vv were imaged using a BD Pathway high-content imaging inverted widefield microscope (BD biosciences) equipped with a 20X 0.75 N.A. objective (Olympus LUCPLFLN). A mercury metal halide lamp combined with an excitation filter (440/10) was used to excite mTurqoise. The fluorescence emission was filtered using a dichroic mirror (458-DiO1) and filters (479/40 and 542/27 for mTurquoise and Venus emission, respectively). Emission was collected by a high-resolution cooled CCD camera (1344x1024 pix, $0.32 \mu \mathrm{m} / \mathrm{pix}$ ). Samples were prepared in a 96 well-plate (microplate BD Falcon) from which the inner 60 wells were used. Cells were pretreated with $100 \mathrm{ng} / \mathrm{ml}$ pertussis toxin for $16 \mathrm{~h}$ or left untreated before adding $3 \mu \mathrm{M}$ AH6809 for $1 \mathrm{~h}$, or $10 \mu \mathrm{M}$ GW627368X for $1 \mathrm{~h}$, with and without $5 \mu \mathrm{M}$ nocodazole for $20 \mathrm{~min}$, Six mTurquoise and Venus emission images were acquired followed by automated addition of PGE2 and subsequent acquisition of another 20 mTurquoise and Venus emission images $\left(t_{\text {lag }}=10 \mathrm{~s}\right)$. The mean fluorescence intensity of the Venus and mTurquoise signal in a cell was corrected by subtraction of the background signal in each image and channel before dividing the Venus over mTurquoise mean fluorescence intensity to obtain the FRET ratio. Values were normalized to the average ratio value of the first six prestimulus data points.

\section{Fluorescence Lifetime Imaging Experiments}

Frequency-domain FLIM experiments on transfected RAW macrophages were performed using a Nikon TE2000-U inverted widefield microscope and a Lambert Instruments Fluorescence Attachment (LIFA; Lambert Instruments) for lifetime imaging. A light-emitting diode (Lumiled LUXEON
III, $\lambda_{\max }=443 \mathrm{~nm}$ ) modulated at $40 \mathrm{MHz}$ was used to excite CFP. Fluorescence detection was performed by a combination of a modulated (40 MHz) image intensifier (II18MD; Lambert Instruments) and a $640 \times 512$ pixel CCD camera (CCD1300QD; VDS Vosskühler). The emission of CFP was detected through a narrow emission filter $(475 / 20 \mathrm{~nm}$; Semrock) to suppress any fluorescence emission from the Citrine fluorophore. FLIM measurements were calibrated with a $1 \mu \mathrm{M}$ solution of pyranine (HPTS), the lifetime of which was set to 5.7 ns. All FLIM images were calculated from phase stacks of 12 recorded images, with exposure times of individual images ranging from 200 to $400 \mathrm{~ms}$. A USH102DH $100 \mathrm{~W}$ mercury lamp (Nikon) was used for acceptor photobleaching. Cells were pretreated with $25 \mu \mathrm{M}$ AH23848 for $1 \mathrm{~h}$ or left untreated and cells were stimulated with $10 \mu \mathrm{M}$ PGE2 or $10 \mu \mathrm{M}$ Butaprost.

\section{Statistics and Reproducibility}

All image processing was performed using Fiji/ImageJ software. Podosome count was performed semi-automatically. Briefly, a median filter ( 3 pixel radius) was applied to the phalloidin image after which the podosome clusters were manually selected. The Fiji maximum finder was subsequently used to detect and count the podosomes. Data from the podosome dissolution assay and the FRET experiments were processed using Microsoft Excel and GraphPad Prism 8 software. Data from the FLIM experiments were analyzed using OriginPro 8. All statistical analyses were performed using GraphPad Prism 8. The specific statistical test, the multiple testing corrections and the number of replicates used for each Figure are specified in the Figure legend. The normality of data distributions was assessed by visual data inspection and the Shapiro-Wilk normality test. $P$-values < 0.05 were considered statistically significant for all experiments. Statistical analyses were only performed for the comparisons indicated in the Figures.

\section{RESULTS}

\section{EP4 Primarily Contributes to Prostaglandin E2-Induced Podosome Dissolution in Dendritic Cells}

To assess the different contributions of EP2 and EP4 in mediating PGE2 signaling in DCs, we first determined whether both EP2 and EP4 signaling can lead to podosome dissolution. For this, we treated immature DCs (iDCs) with PGE2 or well-established and selective EP2 and EP4 agonists and quantified the number of podosomes per cell (Figures 1A, B). In line with our previous observations, the addition of PGE2 resulted in an almost complete loss of podosomes in iDCs. Interestingly, both EP2- and EP4-specific stimulation also reduced the number of podosomes, with EP4 agonist stimulation being slightly more efficient (Figure 1B). These results indicate that individual EP2 and EP4 downstream signaling can both lead to podosome dissolution.

After having established that both EP2 and EP4 signaling can lead to podosome dissolution, we aimed to investigate the 

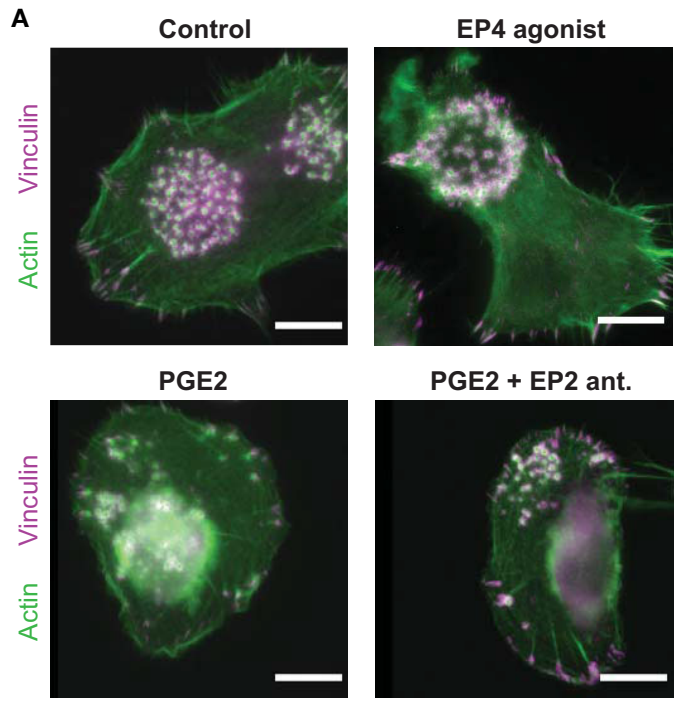

PGE2 + EP2 ant.

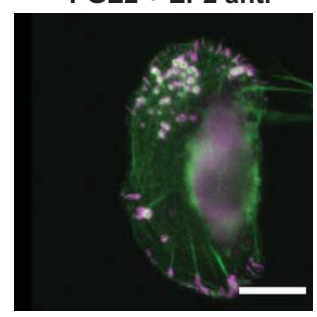

B

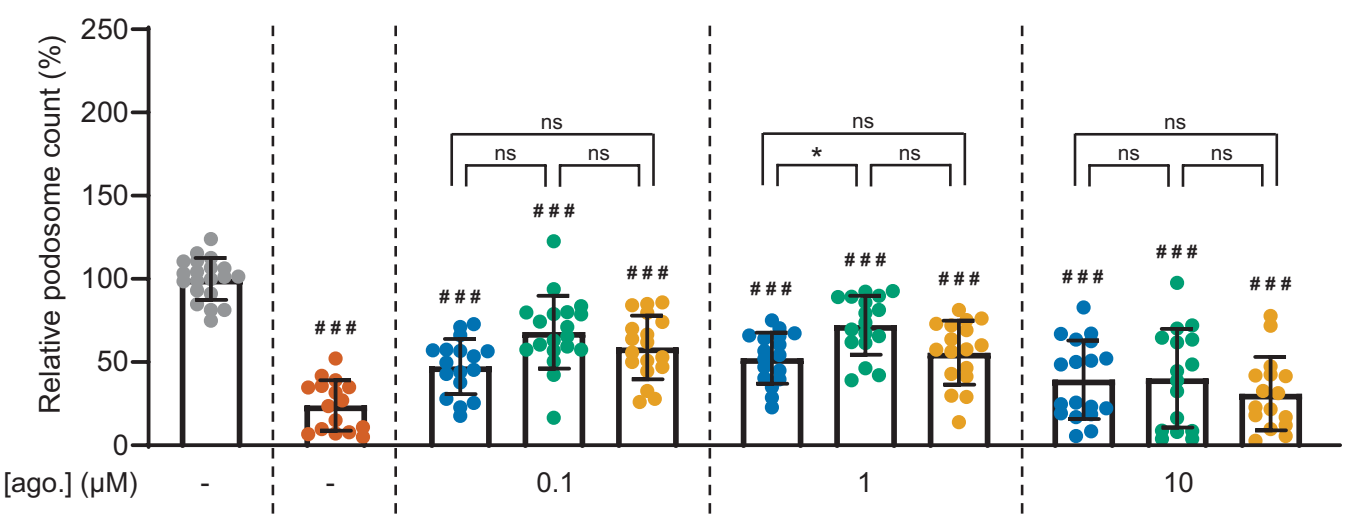

C

- No ant. EP2 ant. EP4 ant. EP2 ant. + EP4 ant.

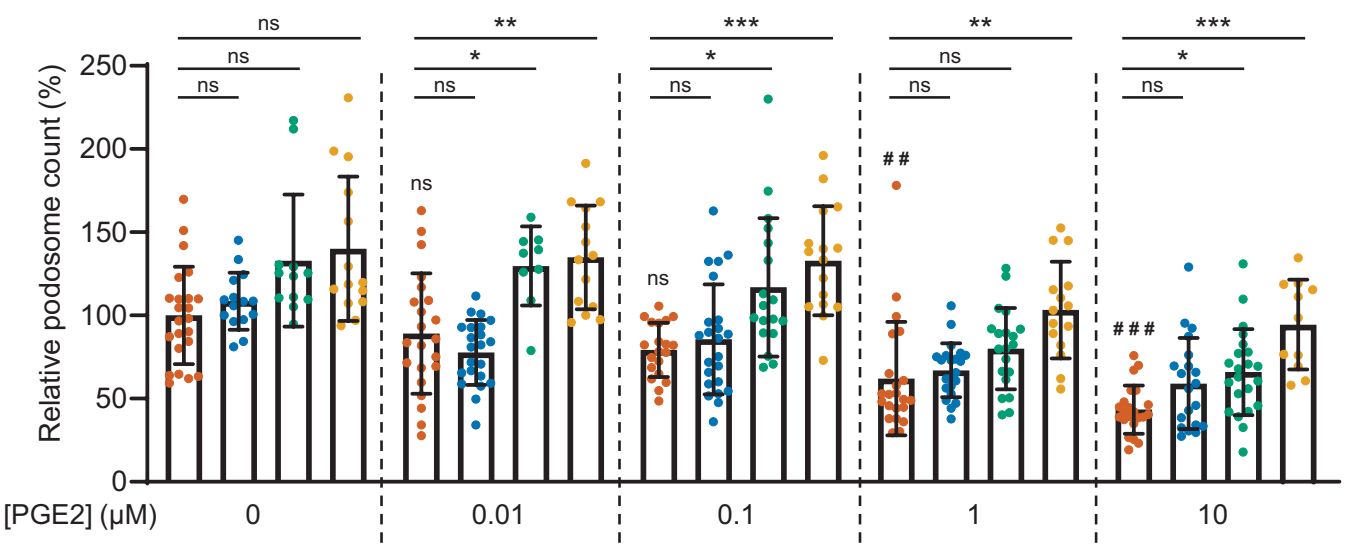




\begin{abstract}
FIGURE 1 | Prostaglandin E2 (PGE2)-induced podosome dissolution in human immature dendritic cells (iDCs) is mostly mediated by EP4. (A) Representative images of PBMC-derived iDCs that were left untreated or were treated with $1 \mu \mathrm{M}$ EP4 agonist L-902688, $1 \mu \mathrm{M}$ EP2 agonist (R)-Butaprost, both $1 \mu \mathrm{M}$ L-902688 and $1 \mu \mathrm{M}(\mathrm{R})$-Butaprost, $1 \mu \mathrm{M}$ PGE2 alone or $1 \mu \mathrm{M}$ PGE2 after pretreatment with EP2 antagonist (ant.) AH6809, EP4 antagonist GW627368X or both AH6809 and GW627368X. Cells were stained for actin (green) and vinculin (magenta). Scale bar $=10 \mu \mathrm{m}$. (B) iDCs were treated with different concentrations of EP2 agonist (ago.) (R)-Butaprost, EP4 agonist L-902688 or both (R)-Butaprost and L-902688. Cells were stained for actin and vinculin and the number of podosomes per image was quantified and normalized to untreated control. Cells treated with $10 \mu \mathrm{M}$ PGE2 were included as positive control. The error bars represent mean \pm SD. Data presented are from two different donors. ns, not significant, ${ }^{\star} \mathrm{P}<0.05$; ${ }^{\# \# \#} \mathrm{P}<0.001$ versus untreated control, Welch ANOVA with Dunnett's T3 multiple comparison test. (C) iDCs were treated with different concentrations of PGE2 with or without pretreatment with EP2 antagonist (ant.) AH6809, EP4 antagonist GW627368X or both AH6809 and GW627368X. Cells were stained for actin and vinculin and the number of podosomes per image was quantified and normalized to untreated control. The error bars represent mean $\pm \mathrm{SD}$. Data presented are from three different donors. ns, not significant, ${ }^{\star} \mathrm{P}<0.05$, ${ }^{\star \star} \mathrm{P}<0.01,{ }^{\star \star \star} \mathrm{P}<0.001 ;{ }^{\# \#} \mathrm{P}<0.01$,

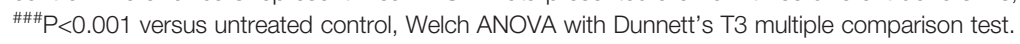

respective contribution of EP2 and EP4 signaling. We reasoned that this would be difficult to assess by using the agonists because of the different affinities for their respective receptor. Therefore, we instead pretreated the cells with well-characterized and selective competitive EP2 and EP4 antagonists to block signaling, followed by the stimulation with the natural ligand PGE2, and subsequently quantified podosome dissolution. Figure 1C shows that inhibition of EP4 attenuates podosome dissolution upon stimulation with $0.01-0.1 \mu \mathrm{M}$ PGE2, while blocking of EP2 has no effect. This indicates that at lower PGE2 concentrations, EP4 is responsible for the induction of podosome loss. Interestingly, at $1 \mu \mathrm{M}$ PGE2, EP4 blocking attenuates podosome dissolution only when EP2 antagonist is coadministered, suggesting that EP2 triggering by PGE2 could somehow influence EP4 activity. At the highest PGE2 concentration $(10 \mu \mathrm{M})$, one cannot fully exclude that the antagonists are not displaced by the PGE2, which complicates the interpretation of these specific results.

Together, these results suggest that EP4 primarily contributes to PGE2-induced podosome dissolution. Importantly, in subsequent experiments we use selective receptor antagonists in combination with the natural ligand PGE2 to define the individual contributions of EP2 and EP4 in mediating PGE2 signaling.

\section{EP2 and EP4 Differentially Stimulate cAMP Production}

PGE2-induced podosome loss in DCs is mediated by the cAMPPKA-RhoA signaling axis downstream of EP2 and EP4 (8). Since our results strongly suggest that EP4 is primarily responsible for podosome loss, we sought to determine whether EP4 induces stronger cAMP responses to PGE2 than EP2. To determine the individual contribution of EP2 and EP4 to the PGE2-induced increase of intracellular cAMP levels, we measured the onset of cAMP production in living RAW macrophages, which endogenously express both EP2 and EP4 (Supplementary Figure 1) (37) and are well-accepted as surrogate cell model to study DCs (38), using ratio measurements of the Förster Resonance Energy Transfer (FRET)-based cAMP sensor tEpac-vv (34). Since the binding of cAMP to $t-E p a c-v v$ reduces FRET between the mTurquoise donor and Venus acceptor fluorophores, a decreased FRET ratio in the macrophages is a direct measure of cAMP production (Figures 2A, B). After the addition of PGE2, cAMP was produced immediately and reached a maximum concentration after about 40 seconds, subsiding to lower levels after 200 seconds (Figure 2C). To compare the cAMP kinetics across different treatment conditions, we quantified the peak of cAMP production and the production rate, as shown in Figure 2D. Both parameters scaled with increasing PGE2 concentrations, indicating that the rate and the magnitude of the induced cAMP response is dose-dependent (Figure 2E).

Compared to PGE2 only, EP2 inhibition led to higher cAMP levels at all tested PGE2 concentrations, while cAMP concentrations subsided to a similar extent (Figure 2F). The PGE2-induced cAMP production rate and CAMP peak remained dose-dependent upon EP2 inhibition as both parameters scaled with PGE2 concentration (Figure 2G). These results indicate that EP2 blockade increases the signaling efficiency of EP4 in response to PGE2. Inhibition of EP4 led to a dramatically different course of cAMP production. In contrast to EP2 inhibition, EP4 inhibition prevented robust cAMP production at PGE2 concentrations up to $0.1 \mu \mathrm{M}$ but allowed a strong cAMP response at $\geq 1 \mu \mathrm{M}$ (Figures $\mathbf{2 H}, \mathbf{I}$ ). Furthermore, this strong cAMP response did not attenuate as observed in the absence of EP4 inhibition. Compared to PGE2 only, the magnitude of the strong cAMP response observed upon EP4 inhibition suggests that EP4 activity may somehow impair the signaling efficiency of EP2. To ascertain that EP2 and EP4 are completely blocked by the antagonist concentrations used in our experiments, we measured cAMP production upon simultaneous inhibition of EP2 and EP4 (Figure 2J). Pretreatment with both antagonists effectively inhibited total cAMP production at 0.1 and $1 \mu \mathrm{M}$ PGE2, showing that both receptors are completely blocked at physiological concentrations of PGE2 (Figures 2J, K). Importantly, since $10 \mu \mathrm{M}$ PGE2 still induced a small amount of cAMP, even in the presence of both antagonists (Figure 2J), we decided to omit this condition in subsequent experiments, since either one or both of the antagonist may be displaced by the high concentration of PGE2.

Our results demonstrate that the selective stimulation of EP2 and EP4 by PGE2 induces kinetically distinct cAMP production profiles. While PGE2-EP4 signaling results in a fast and transient cAMP production that increases proportionally to the ligand concentrations, PGE2-EP2 signaling is induced only by PGE2 concentrations of $1 \mu \mathrm{M}$ and higher, and cAMP elevation is more prolonged. We also show that co-stimulation of EP2 and EP4 mutually dampens their signaling efficiency, as both receptors induce higher cAMP production when they are individually triggered by PGE2. 
A

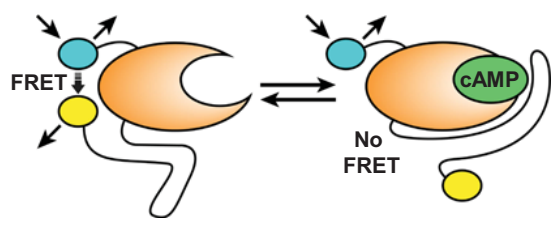

B

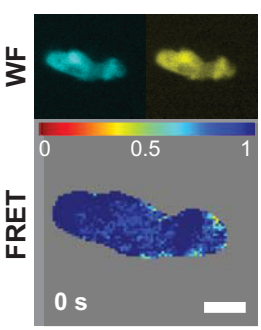

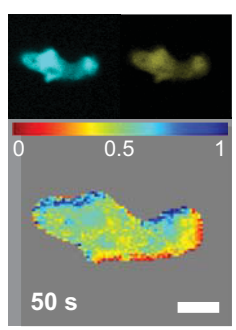

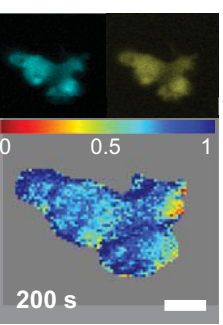

E

- Control $\frac{[\mathrm{PGE2}](\mu \mathrm{M})}{0.01 \bullet 0.1 \bullet 1 \bullet 10}$
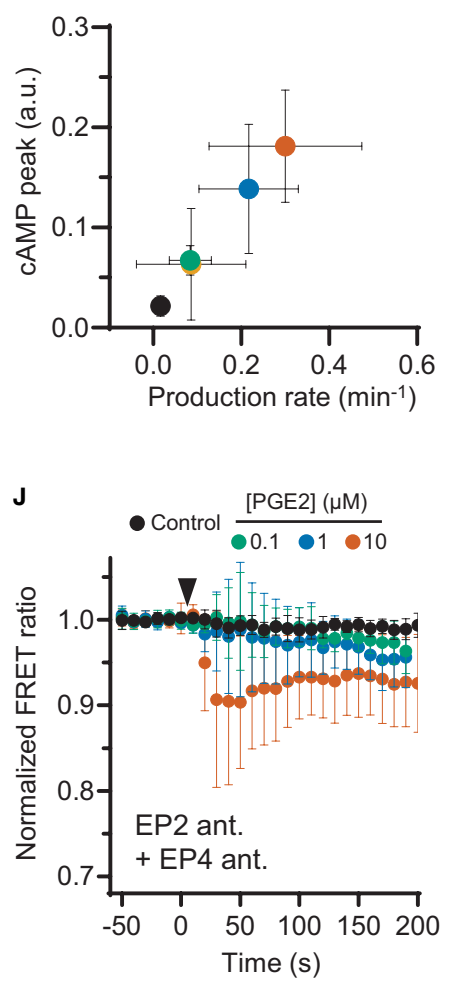

$\mathbf{F}$

G
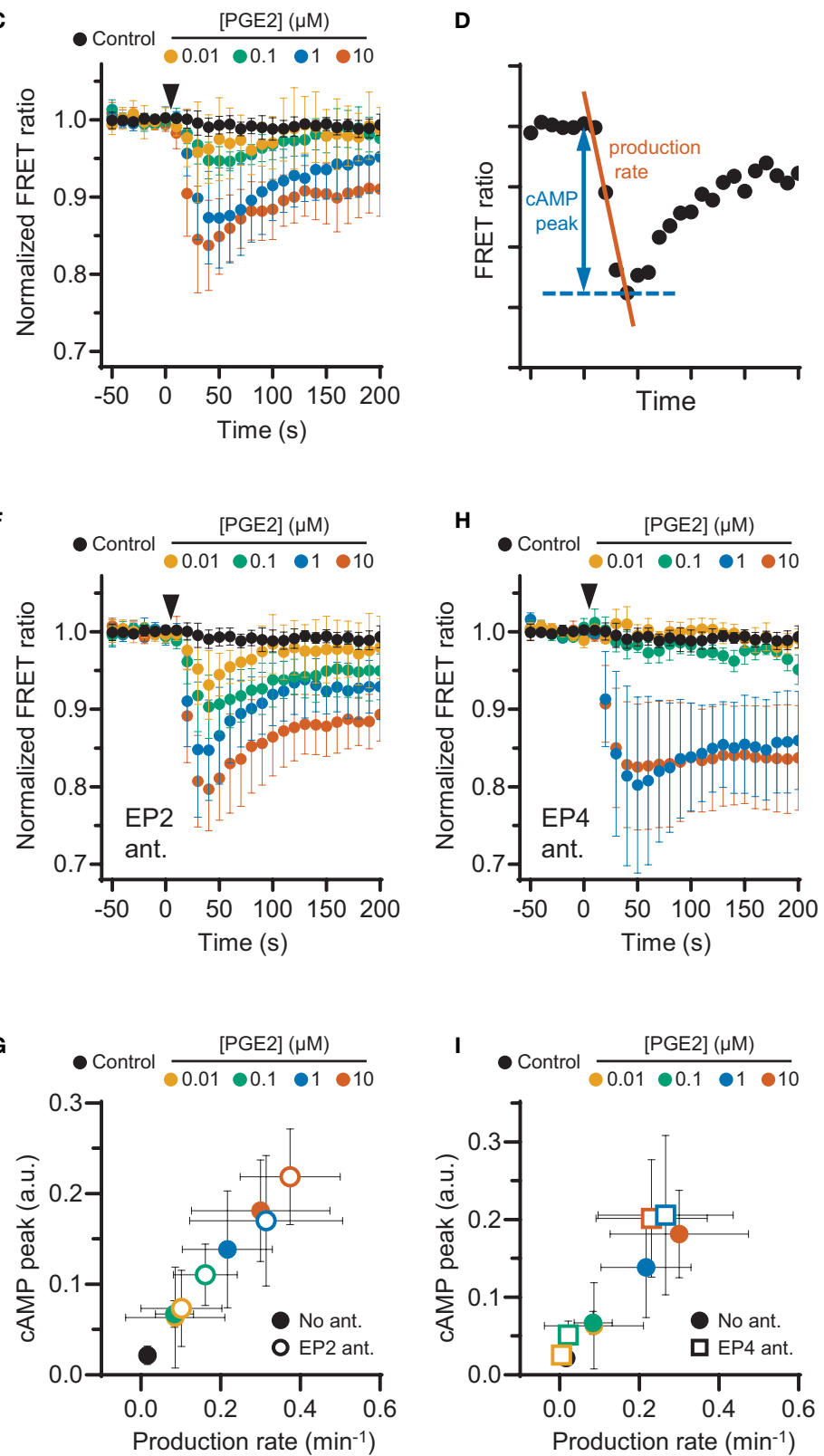

D

I C Control $\frac{[\text { PGE2] }(\mu \mathrm{M})}{0.01 \bullet 0.1 \bullet 10}$

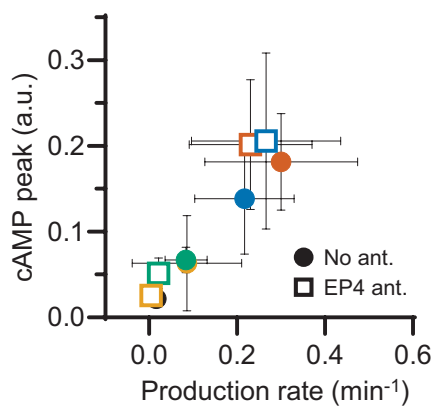

K Control $\frac{[\mathrm{PGE} 2](\mu \mathrm{M})}{0.1}$

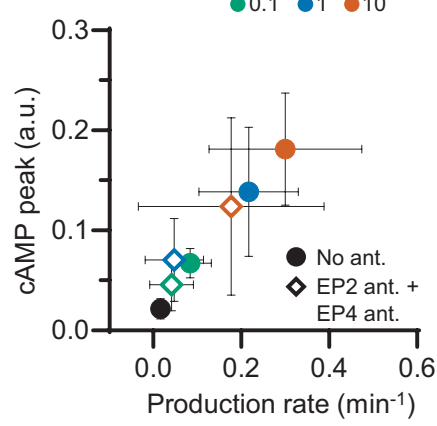

FIGURE 2 | Continued 
FIGURE 2 | EP2 and EP4 induce distinct cyclic adenosine monophosphate (CAMP) responses. (A) Schematic illustration of intramolecular cAMP FRET sensor tEpac-w. Binding of cAMP to t-Epac-w reduces Förster Resonance Energy Transfer (FRET) between the mTurquoise donor and Venus acceptor fluorophores of tEpac-w, making a decreased ratio of the fluorescent intensities a direct measure of cAMP accumulation [adapted from (34)]. (B) The mTurquoise (cyan) and Venus (yellow) signal were acquired with widefield microscopy (WF panels). After background subtraction in each image and channel, the FRET ratio was calculated as the Venus intensity over the mTurquoise intensity for each timepoint and was normalized to the average of prestimulus values (FRET panels). Normalized FRET values range from 0 (red) to 1 (blue). Scale bar $=5 \mu \mathrm{m}$. (C) FRET ratios of t-Epac-vv before and after the addition of different prostaglandin E2 (PGE2) concentrations were measured in transiently transfected RAW macrophages. A control was performed with the addition of buffer only. The data presented are mean \pm SD from $\geq 5$ cells per condition. (D) Example FRET curve that illustrates the definition of the relative cAMP peak and CAMP production rate. The amplitude of the cAMP peak was defined as the maximal decrease in FRET ratio. The CAMP production rate was quantified by determining the slope between the final prestimulus timepoint and the timepoint at which minimal FRET ratios were observed using a linear fit over all included timepoints. (E) The cAMP production peak and the cAMP production rate were measured from the FRET curve of individuals cells from (C) and the average peak was plotted as a function of the average production rate per condition. The error bars represent SD for both parameters. (F, H, J) FRET ratios were measured after the addition of PGE2 in cells pretreated with EP4 antagonist (ant.) GW627368X (F), pretreated with EP2 antagonist AH6809 $\mathbf{( H )}$ or pretreated with both GW627368X and AH6809 $(\mathbf{J})$. The data presented are mean \pm SD from $\geq 4$ cells per condition. (G, I, K) The relative cAMP production peak and the cAMP production rate were measured from (F, H, J), respectively. The error bars represent SD for both parameters.
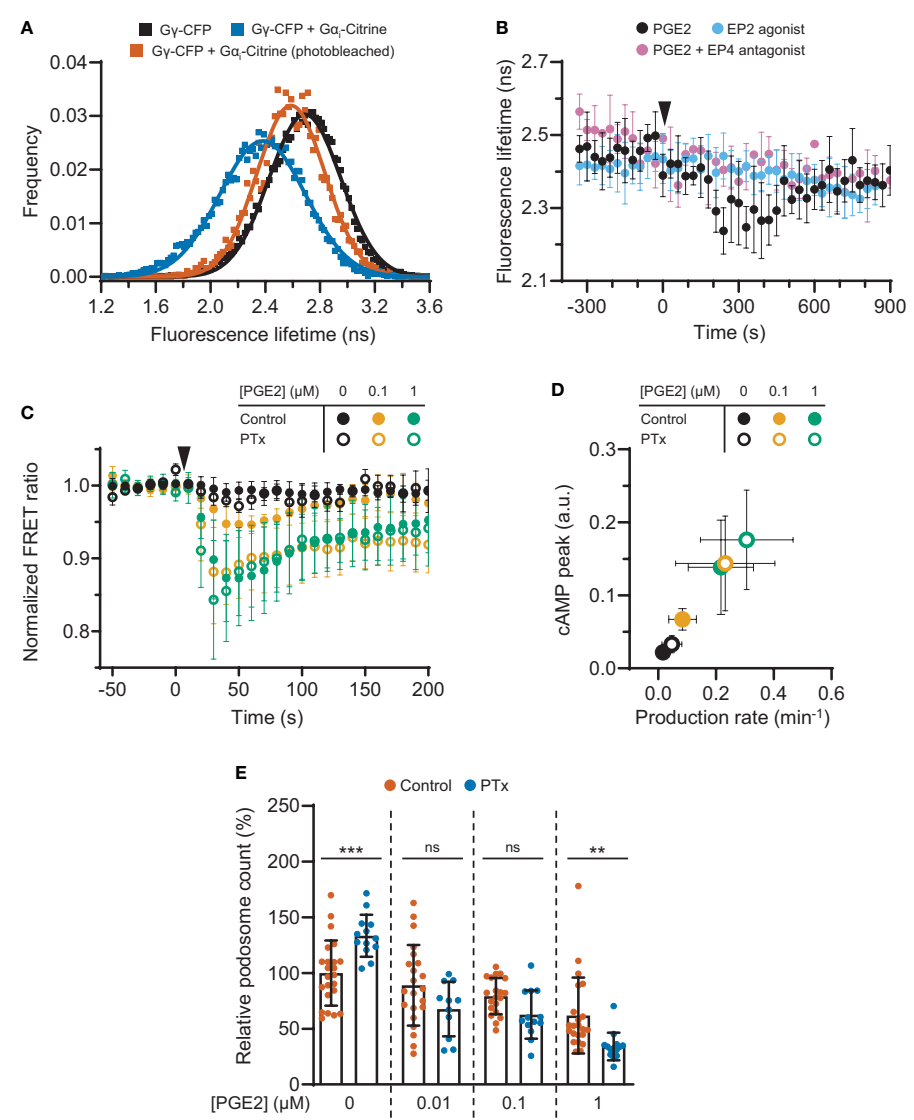

FIGURE 3 | EP4-coupled $\mathrm{Ga}_{i}$ dampens the prostaglandin E2 (PGE2)-induced cyclic adenosine monophosphate (cAMP) production. (A) RAW macrophages were

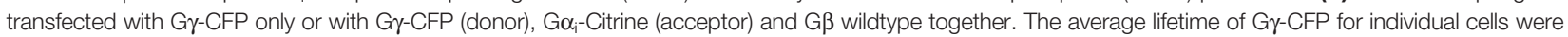
calculated from frequency-domain FLIM images and the distributions were fitted with a Gaussian profile (solid lines) to obtain the average lifetimes. Photobleaching of Go $\alpha_{i}$-Citrine was used as a control for the occurrence of FRET. (B) The average donor lifetime in cells expressing both donor and acceptor is plotted before and after addition of $10 \mu \mathrm{M}$ PGE2 in absence or presence of EP4 antagonist AH23848 or after addition of $10 \mu \mathrm{M}$ EP2 agonist Butaprost. The data presented are mean \pm SD from $\geq 2$ cells. (C) FRET ratios of t-Epac-wv before and after addition of PGE2 were measured in transiently transfected RAW macrophages that were left untreated or were pretreated with $\mathrm{G} \alpha_{i}$ inhibitor pertussis toxin (PTx). Controls were performed with the addition of buffer only. The data presented are mean \pm SD of measurements from $\geq 4$ cells per condition. (D) The CAMP peak and the CAMP production rate were quantified as described in Figure 2D from (C) and the average peak was plotted as a function of the average production rate per condition. The error bars represent SD for both parameters. (E) iDCs were treated with different concentrations of PGE2 with or without PTx pretreatment. Cells were stained for actin and vinculin and the number of podosomes per image was quantified and normalized to untreated control. The error bars represent mean $\pm S D$. Data presented are from three different donors. ${ }^{\star \star} P<0.01,{ }^{\star \star *} P<0.001, W e l c h$ ANOVA with Dunnett's T3 multiple comparison test. 


\section{EP4-Coupled $\mathrm{G} \alpha_{\mathrm{i}}$ Fine-Tunes the Prostaglandin E2-Induced cAMP Production}

Given that EP2 and EP4 differentially control cAMP dynamics, we sought to identify factors that contribute to these differences. Since the inhibitory $\mathrm{G}$ protein $\mathrm{G} \alpha_{\mathrm{i}}$ has been shown to couple to EP4 (22), we hypothesized that $G \alpha_{i}$ dampens the PGE2-induced cAMP response in cells expressing EP4. To demonstrate that EP4 selectively activates $G \alpha_{i}$ also in macrophages, we performed fluorescence lifetime imaging (FLIM) to measure FRET between cyan fluorescent protein (CFP)-tagged $\mathrm{G} \gamma(\mathrm{G} \gamma$-CFP) and Citrine-tagged $\mathrm{G \alpha}_{\mathrm{i}}\left(\mathrm{G \alpha}_{\mathrm{i}}\right.$-Citrine). The fluorescent lifetime of the FRET donor (CFP) decreased upon co-expression with the acceptor (Citrine) and was restored to control levels upon acceptor photobleaching (Figure 3A), indicating that FRET occurred between $\mathrm{G} \gamma$-CFP and $\mathrm{G \alpha}_{\mathrm{i}}$-Citrine. Since $\mathrm{G \alpha}_{\mathrm{i}}$ is known to undergo conformational rearrangements upon activation (39) and FRET between $\mathrm{G} \gamma$-CFP and $\mathrm{G \alpha}_{\mathrm{i}}$-Citrine is likely affected by such rearrangements, a shift in fluorescence lifetime is expected upon EP4 stimulation. Treatment with PGE2 induced a gradual reduction in the lifetime of the donor fluorophore, whereas no shift in the lifetime phase was observed upon either inhibition of EP4 or selective stimulation of EP2 (Figure 3B). These findings confirm that PGE2 induces $\mathrm{G} \alpha_{\mathrm{i}}$ activation via EP4 only.

To determine the consequences of EP4-mediated $\mathrm{G \alpha}_{\mathrm{i}}$ activation on PGE2 signaling, we measured cAMP elevation using t-Epac-vv upon inhibition of $\mathrm{G}_{\alpha_{i}}$ with pertussis toxin (PTx). $\mathrm{G \alpha}_{\mathrm{i}}$ blockade significantly enhanced the cAMP peak concentrations and production induced by $0.1 \mu \mathrm{M}$ PGE2 and to a lower extent also by $1 \mu \mathrm{M}$ PGE2 (Figure 3C), indicating that $\mathrm{Go}_{\mathrm{i}}$ attenuates cAMP production most strongly at lower PGE2 concentrations. The effect of $\mathrm{G \alpha}_{\mathrm{i}}$ inhibition on cAMP production is more clearly depicted in Figure 3D, where a higher cAMP peak and an increased production rate are observed after addition of PTx.

Next, to investigate whether EP4-mediated $\mathrm{G \alpha}_{\mathrm{i}}$ activation would dampen cAMP-dependent processes such as podosome dissolution, we determined PGE2-mediated podosome loss in iDCs with or without PTx treatment. We found that $G \alpha_{i}$ inhibition led to slightly increased podosome loss at all PGE2 concentrations tested, with $1 \mu \mathrm{M}$ PGE2 being statistically significant while 0.01 and $0.1 \mu \mathrm{M}$ PGE2 show a non-significant but clear trend (Figure 3E). It should be considered that such low concentrations of PGE2 are less powerful in inducing podosome dissolution (Figure 1C), making the effect of PTx treatment more difficult to assess. Nonetheless, this result indicates that the $\mathrm{G} \alpha_{\mathrm{i}}$-mediated dampening of cAMP production also affects cellular decisions downstream of EP2 and EP4.

Together, these findings show that $\mathrm{G \alpha}_{\mathrm{i}}$ dampens the onset of cAMP production, suggesting that the PGE2-EP4-G $\alpha_{i}$ axis might act as signaling gatekeeper when low PGE2 levels fluctuate slightly.

\section{EP2- and EP4-Mediated Signaling Requires Cortical Microtubule Integrity}

Since the interplay between G proteins and tubulin is well documented as well as their localization along microtubules (40-
42), we investigated whether microtubule integrity is important for PGE2-induced cAMP production. We found that microtubule disruption (Supplementary Figure 2) deregulates PGE2-induced cAMP elevation (Figure 4A). More specifically, when both receptors are activated, attenuation of the cAMP response by nocodazole was only observed at $1 \mu \mathrm{M}$ PGE2 and not at $0.1 \mu \mathrm{M}$ PGE2 (Figures 4A, B). Upon EP2 inhibition, however, the cAMP production rate and the maximum cAMP levels induced by PGE2EP4 were reduced at all PGE2 concentrations tested (Figures 4C, D). Finally, EP4 inhibition revealed that the strong and sustained cAMP response of PGE2-EP2 is completely prevented by microtubule disruption (Figures 4E, F). These results demonstrate that the $\mathrm{G \alpha}_{\mathrm{s}}$-mediated cAMP response to PGE2 relies on an intact microtubule network and that disruption of this network reduces the signaling efficiency of both EP2 and EP4, with EP2 activity being more sensitive to microtubule integrity than EP4 activity.

\section{DISCUSSION}

This study characterized the EP2 and EP4 signaling modalities to better understand DC and macrophage responses elicited by PGE2. Our first important observation is that selective activation of EP2 and EP4 by agonists leads to different outcomes compared to activation by PGE2 in the presence of selective receptor antagonists. More specifically, when the receptors are individually activated by a selective agonist, podosome dissolution is almost equally induced by EP2 and EP4, whereas podosome dissolution is mostly mediated by EP4 after the addition of natural ligand PGE2 in the presence of selective antagonists. Throughout this study, we consistently applied selective antagonists to determine individual receptor contributions to PGE2 signaling and show that 1) both EP2 and EP4 signal more efficiently when selectively activated by their natural ligand PGE2; 2) EP4 induces dose-dependent and transient cAMP production, whereas EP2 induces a sustained cAMP response only at high PGE2 concentration; 3) EP4-linked $G \alpha_{i}$ dampens both PGE2-induced cAMP generation and podosome dissolution; 4) microtubule disruption obstructs efficient signaling of both receptors, especially affecting EP2 strongly.

We here also show that PGE2-induced podosome loss in iDCs (18) is differentially controlled by EP2 and EP4. PGE2-induced podosome dissolution is a first step toward the acquisition of a fast migratory phenotype by DCs $(18,43)$. In fact, PGE2 is an important factor to induce DC maturation and by using selective agonists, both EP2 and EP4 have been proposed to play similar roles in this process $(6,16)$. Our results suggest that this might not be the case and that EP4 is likely the most predominant receptor in mediating the PGE2 signaling that leads to podosome dissolution and the induction of migratory mature DCs. This is in line with previous findings in gene-targeting experiments in mice, where PGE2-EP4 signaling was found to promote migration and maturation of Langerhans cells, thereby initiating skin immune responses (44). Similarly, other PGE2-mediated immunological processes such cytokine production and $\mathrm{T}$ cell activation have been reported to be controlled differently by EP2 and EP4 (45-47). Knockdown of 
A

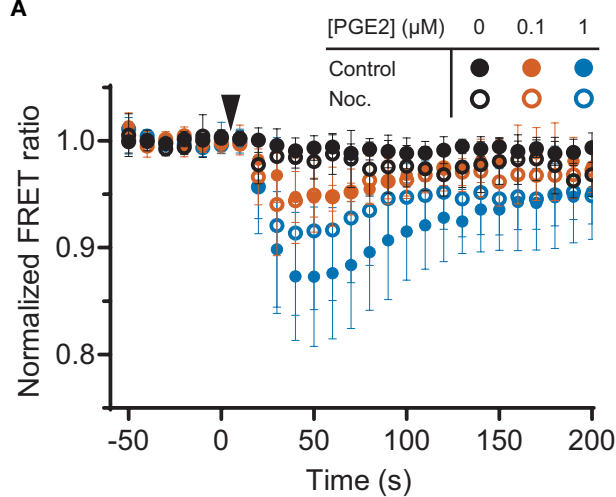

C

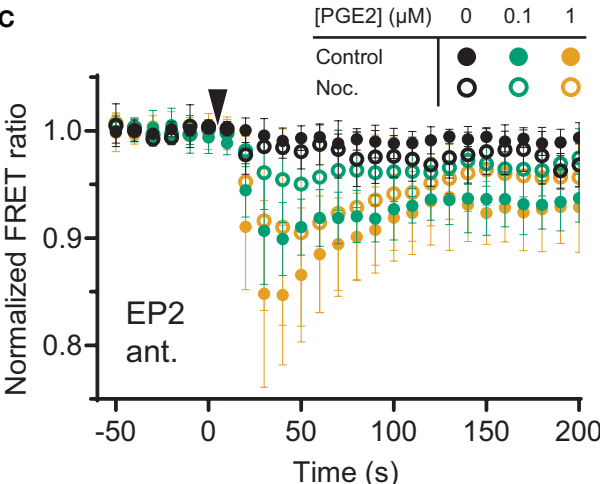

E

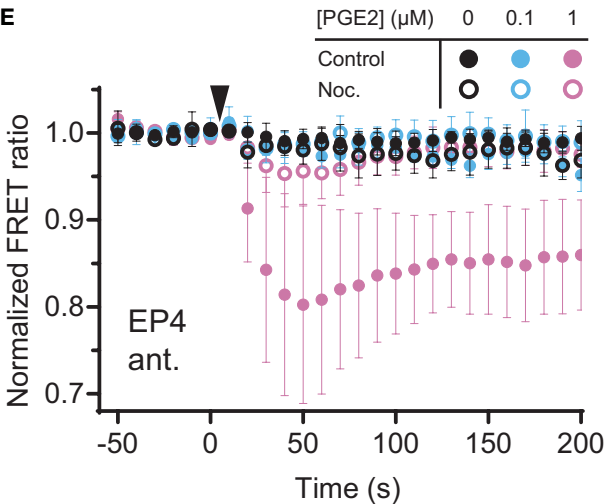

B
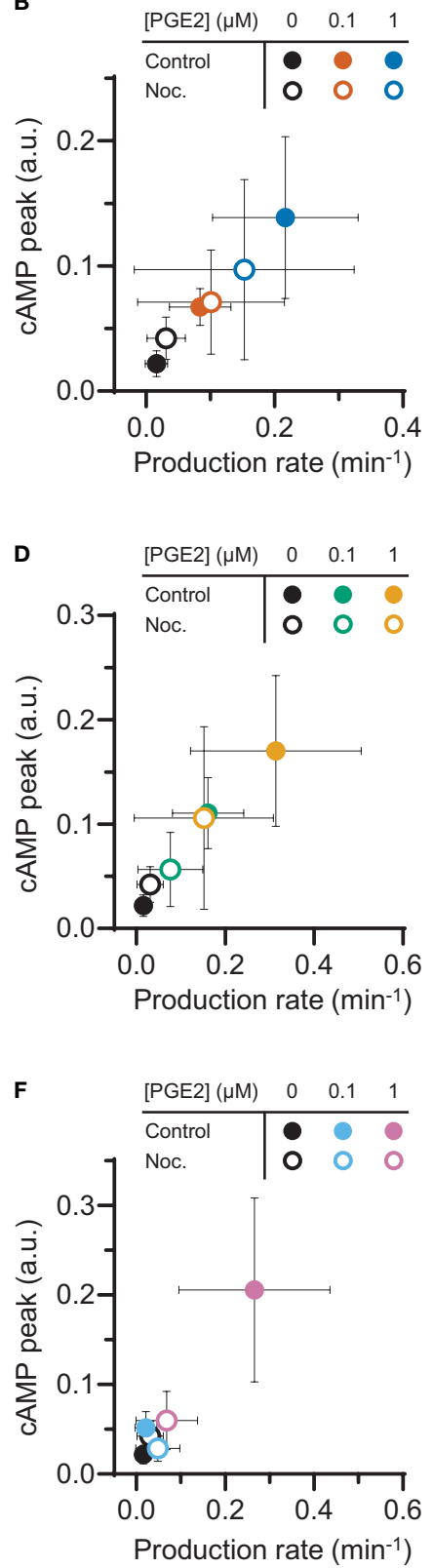

FIGURE 4 | Efficient signaling of EP2 and EP4 relies on microtubule integrity. (A, C, E) The Förster Resonance Energy Transfer (FRET) ratio of t-Epac-w was measured in cells that were untreated or pretreated with nocodazole (Noc.) before and after addition of prostaglandin E2 (PGE2). Shown are the ratios obtained in cells in the absence of antagonists (A), in the presence of EP2 antagonist AH6809 (C) or EP4 antagonist GW627368X (E). Controls were performed with the addition of buffer only. The data are mean \pm SD from $\geq 5$ cells per condition. (B, D, F) The cyclic adenosine monophosphate (cAMP) production peak and the cAMP production rate were measured from the FRET curve of individual cells from (A, C, E), respectively, and the average peak was plotted as a function of the average production rate per condition. The error bars represent SD for both parameters.

EP2 or EP4 in DCs possibly in combination with the use of agonists and antagonists might eventually help to clarify these differences. However, since EP2 and EP4 are always co-expressed in DCs, it remains to be determined whether the knockdown of one receptor does not affect expression patterns of the other receptor.
Early studies characterizing the EP receptor signaling capacity have mostly used cells that overexpress either EP2 or EP4 (22, 23, $25,48-50$ ), which makes it challenging to determine the differential contribution of the receptors when they are co-expressed. Here, we have addressed this question and measured the early onset of cAMP 
production in cells that endogenously express both EP2 and EP4. Using selective EP2 and EP4 antagonists, we demonstrate that EP2 induces sustained CAMP, whereas EP4-mediated cAMP production is faster but more transient. This difference may partially be explained by the fact that EP4, and not EP2, is internalized shortly after stimulation with PGE2, which halts further signaling $(23,51)$. Furthermore, our results showing a sustained EP2-induced cAMP production are in line with the previous observation that EP2 is the main cAMP generator after extended PGE2 stimulation (48). We also know that EP4 can couple to both $\mathrm{G} \alpha_{\mathrm{s}}$ and $\mathrm{G} \alpha_{\mathrm{i}}(22)$. Here, we provide additional evidence that $\mathrm{G} \alpha_{i}$ is only linked to EP4 and not to EP2, and that $\mathrm{G}_{\mathrm{i}}$ attenuates the cAMP response induced by low PGE2 concentrations. Given that several GPCRs do not precouple with $G \alpha_{i}$ (52), it would be important to determine how and when EP4 and $\mathrm{G} \alpha_{i}$ interact. In a recent study, hidden Markov modeling classified $G$ proteins into four diffusion states, of which the slowest two states represent $G$ proteins that interact in hot spots for GPCR activation (53). The same study employed singlemolecule tracking to show that adrenergic receptors and $G \alpha_{i}$ proteins interact only transiently within these hot spots (53). Single-molecule imaging methods are excellent tools to understand the fundamental principles of $G$ protein dynamics and could be exploited to better understand the molecular mechanisms regulating the spatiotemporal interaction between EP4 and $G \alpha_{s}$ or $G \alpha_{i}$, which could shape the cAMP production profile.

Our FRET measurements also reveal that the cAMP response of EP4 is dose-dependent, whereas the EP2-induced cAMP production is negligible at low PGE2 concentrations and strong at high PGE2 concentrations. EP4 has a higher affinity for PGE2 than EP2, as indicated by dissociation constants of 0.59 $\mathrm{nM}$ and $13 \mathrm{nM}$, respectively (54). The high affinity of EP4 explains its responsiveness to low PGE2 concentrations, but the apparent irresponsiveness of EP2 to PGE2 concentrations below $1 \mu \mathrm{M}$ cannot be explained by its lower affinity for PGE2, based on the magnitude of its dissociation constant. Therefore, additional mechanisms that mediate the all-or-nothing response of EP2 could exist and might include receptor hetero- or homooligomerization, which are documented for other GPCRs (55) but remain to be identified for EP2 and EP4. Importantly, our results indicate that EP4 is the main producer and regulator of cAMP production at low, possibly physiological, PGE2 concentrations, whereas EP2 boosts cAMP levels only when PGE2 concentration increases above a certain threshold, as could (locally) occur in inflamed or tumor tissues.

Interestingly, our experiments using a cAMP FRET biosensor show that EP2 and EP4 both signal more strongly when stimulated selectively. This indicates that simultaneous activation of both receptors limits efficient signaling and suggests the presence of signaling crosstalk between EP2 and EP4. Since both EP2 and EP4 couple to $G \alpha_{s}$, competition for downstream effectors could contribute to the attenuated cAMP response observed in the absence of receptor antagonists. Additionally, inhibitory interactions between activated receptors at the plasma membrane could attenuate the PGE2induced cAMP response to establish an integrated signal that
A

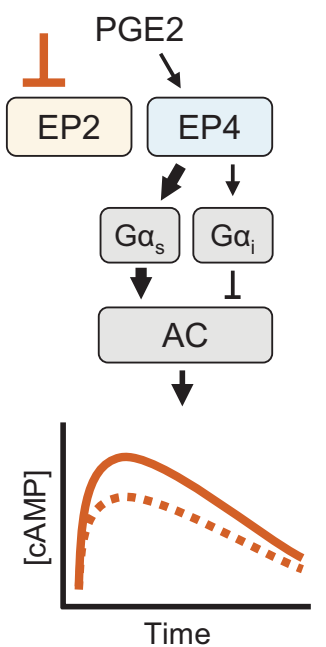

B

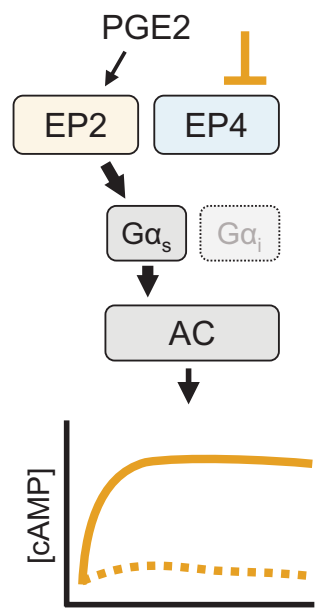

Time
C

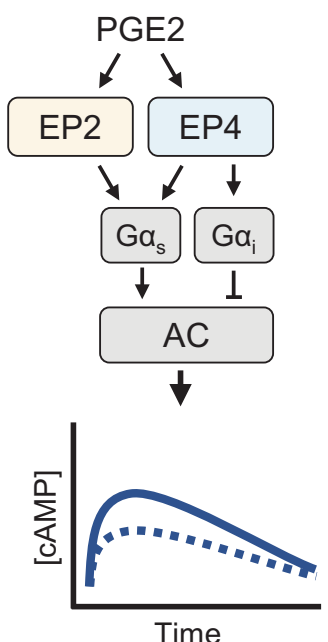

Time

Intact microtubules $\quad \ldots$ Disrupted microtubules

FIGURE 5 | Schematic overview of the cyclic adenosine monophosphate (cAMP) responses induced by EP2 and EP4. (A) When only EP4 is active, both Go, and $\mathrm{G} \alpha_{i}$ control AC activity. G $\alpha_{s}$ induces a dose-dependent cAMP response that is dampened by $\mathrm{G} \alpha_{\mathrm{i}}$. The cAMP signal subsides over time and is attenuated by microtubule disruption. (B) When EP2 is activated selectively, only G $\alpha_{s}$ modulates AC activity. The resulting cAMP response is either weak or strong, does not subside and completely relies on an intact microtubule network. (C) When both EP2 and EP4 are active, competition for Go $\alpha_{s}$ dampens the integrated cAMP response. Signaling crosstalk between EP2 and EP4 allows the cell to respond differently to prostaglandin E2 (PGE2) depending on the organization and expression of EP2 and EP4. 
fine-tunes downstream effects. Although the mechanisms underlying this potential crosstalk remains to be deciphered, our results strongly indicate that the EP2 and EP4 signaling axes may be closely intertwined.

The organization of GPCR signaling has previously been linked to membrane domains and the cortical microtubule network (56). Here, we show that an intact microtubule network (and possibly microtubule dynamic properties too, as shown in Supplementary Figure 2B) is necessary for efficient signaling of both EP2 and EP4. Remarkably, several other studies show that cAMP production is dampened by intact microtubules and lipid membrane domains (56-58). Specifically, microtubules were suggested to restrict the interactions of $\mathrm{G} \alpha_{\mathrm{s}}$ with GPCRs and $\mathrm{AC}$, limiting the efficiency of cAMP responses $(57,59)$. Yet, most previous research focused on adrenergic receptors, which primarily localize to lipid-raft domains (60). By contrast, the insensitivity of EP receptors to cholesterol depletion suggests that EP2 and EP4 mainly localize in non-raft regions (61). Moreover, the $\mathrm{AC}$ isoform 2, which is the $\mathrm{AC}$ isoform that responds most strongly to PGE2, is also located in non-raft domains, further supporting the notion that PGE2 signaling occurs outside lipid rafts and possibly explaining their differential dependence on the microtubule network that was reported for the adrenergic receptors (61). Although a mechanistic explanation is still lacking, the different sensitivity of EP2 and EP4 to microtubule disruption is striking: whereas PGE2-EP4 signaling is partially reduced, PGE2-EP2 signaling is completely abolished by nocodazole treatment. Imaging of microtubules in combination with single-particle tracking of EP receptors could reveal the role of microtubules in PGE2 signaling. Furthermore, a detailed molecular investigation of $G \alpha_{s}$ and $G \alpha_{i}$ dynamics is required to accurately describe the organization and receptor-coupling of the different $\mathrm{G} \alpha$ proteins involved. The different sensitivity of EP2 and EP4 to nocodazole together with the apparently contradictory results between adrenergic and prostaglandin receptors strongly emphasizes the complexity of GPCR spatiotemporal organization and the importance of studying the regulation of a specific receptor in its endogenous settings.

Based on our experimental observations, we here present a schematic model for the cAMP responses established by EP2 and EP4. Upon selective stimulation of EP4, both $G \alpha_{s}$ and $G \alpha_{i}$ proteins are activated (Figure 5A). Active $\mathrm{G} \alpha_{s}$ proteins modulate the activity of $\mathrm{AC}$, resulting in a strong cAMP response. $\mathrm{G \alpha}_{\mathrm{i}}$ functions to finetune the cAMP production at low PGE2 concentrations. As EP4 is subjected to desensitization and internalization $(23,25)$, the elicited cAMP response subsides over time. When EP2 is selectively stimulated instead, only $\mathrm{G} \alpha_{\mathrm{s}}$ controls AC activity (Figure 5B). The resulting cAMP response does not subside because EP2 is insensitive to receptor desensitization and internalization (23). Disruption of the microtubule network dampens the cAMP levels induced by both EP2 and EP4, albeit with different strength, showing that microtubules play an important role in the organization of EP receptor signaling. Upon simultaneous activation of EP2 and EP4, G $\alpha$ proteins are activated by both EP2 and $\mathrm{EP} 4$, resulting in an integrated cAMP response (Figure $5 \mathrm{C}$ ).
Competition between EP2 and EP4 for $\mathrm{G}_{\mathrm{s}}$ likely reduces the signaling efficiency of individual receptors and thereby moderates final cAMP levels. Since EP4 has a higher affinity for PGE2 than EP2 (54), EP4 is the main gatekeeper of cAMP levels, especially at low PGE2 concentrations, while EP2 becomes important only at high PGE2 concentrations that will result in strong and sustained cAMP production.

Increased PGE2 concentrations have been reported in the tumor microenvironment of several cancer types (9-12). Since PGE2 regulates immune cell function, the selective modulation of EP receptor signaling pathways has been proven to enhance the antitumor immune response (62-64). Further insight into the concerted action of EP2 and EP4 will be essential to efficiently control the cellular responses to PGE2.

\section{DATA AVAILABILITY STATEMENT}

The raw data supporting the conclusions of this article will be made available by the authors, without undue reservation.

\section{AUTHOR CONTRIBUTIONS}

$\mathrm{WV}, \mathrm{KD}, \mathrm{BJ}, \mathrm{SK}$ performed the experiments and analyzed the data. DL provided the analytical tools. WV, KD, DL, and AC wrote the manuscript with input from all authors. DL and AC supervised the entire project. All authors contributed to the article and approved the submitted version.

\section{FUNDING}

This work was supported by a Human Frontiers Science Program grant awarded to DL and AC (RGY0074/2008) and by a NIH R35GM-126934 grant awarded to DL.

\section{ACKNOWLEDGMENTS}

The microscopy experiments were mostly conducted at the Radboudumc Technology Center Microscopy with the exception of the FLIM measurements that were performed at the University of Twente, Enschede, The Netherlands.

\section{SUPPLEMENTARY MATERIAL}

The Supplementary Material for this article can be found online at: https://www.frontiersin.org/articles/10.3389/fimmu.2020.613286/ full\#supplementary-material 


\section{REFERENCES}

1. Pierce KL, Premont RT, Lefkowitz RJ. Seven-transmembrane receptors. Nat Rev Mol Cell Biol (2002) 3:639-50. doi: 10.1038/nrm908

2. Smith WL. Prostanoid biosynthesis and mechanisms of action. Am J Physiol (1992) 263:F181-91. doi: 10.1152/ajprenal.1992.263.2.F181

3. Coleman RA, Smith WL, Narumiya S. International Union of Pharmacology classification of prostanoid receptors: properties, distribution, and structure of the receptors and their subtypes. Pharmacol Rev (1994) 46:205-29.

4. Legler DF, Bruckner M, Uetz-von Allmen E, Krause P. Prostaglandin E2 at new glance: novel insights in functional diversity offer therapeutic chances. Int J Biochem Cell Biol (2010) 42:198-201. doi: 10.1016/j.biocel.2009.09.015

5. Narumiya S. Prostanoids in immunity: roles revealed by mice deficient in their receptors. Life Sci (2003) 74:391-5. doi: 10.1016/j.lfs.2003.09.025

6. Legler DF, Krause P, Scandella E, Singer E, Groettrup M. Prostaglandin E2 is generally required for human dendritic cell migration and exerts its effect via EP2 and EP4 receptors. J Immunol (2006) 176:966-73. doi: 10.4049/ jimmunol.176.2.966

7. Gualde N, Harizi H. Prostanoids and their receptors that modulate dendritic cell-mediated immunity. Immunol Cell Biol (2004) 82:353-60. doi: 10.1111/ j.0818-9641.2004.01251.x

8. van Helden SF, Oud MM, Joosten B, Peterse N, Figdor CG, van Leeuwen FN. PGE2-mediated podosome loss in dendritic cells is dependent on actomyosin contraction downstream of the RhoA-Rho-kinase axis. J Cell Sci (2008) 121:1096-106. doi: 10.1242/jcs.020289

9. Rasmuson A, Kock A, Fuskevåg OM, Kruspig B, Simón-Santamaría J, Gogvadze V, et al. Autocrine Prostaglandin E2 Signaling Promotes Tumor Cell Survival and Proliferation in Childhood Neuroblastoma. PloS One (2012) 7:e29331. doi: 10.1371/journal.pone.0029331

10. Rigas B, Goldman IS, Levine L. Altered eicosanoid levels in human colon cancer. J Lab Clin Med (1993) 122:518-23. doi: 10.5555/uri:pii:002221439 $390010 \mathrm{~V}$

11. Howe LR. Inflammation and breast cancer. Cyclooxygenase/prostaglandin signaling and breast cancer. Breast Cancer Res (2007) 9:210. doi: 10.1186/ bcr1678

12. Huang M, Stolina M, Sharma S, Mao JT, Zhu L, Miller PW, et al. Non-Small Cell Lung Cancer Cyclooxygenase-2-dependent Regulation of Cytokine Balance in Lymphocytes and Macrophages: Up-Regulation of Interleukin 10 and Down-Regulation of Interleukin 12 Production. Cancer Res (1998) 58:1208-16

13. Kobayashi K, Omori K, Murata T. Role of prostaglandins in tumor microenvironment. Cancer Metastasis Rev (2018) 37:347-54. doi: 10.1007/ s10555-018-9740-2

14. Ma Y, Shurin GV, Peiyuan Z, Shurin MR. Dendritic cells in the cancer microenvironment. J Cancer (2013) 4:36-44. doi: 10.7150/jca.5046

15. Klarquist JS, Janssen EM. Melanoma-infiltrating dendritic cells: Limitations and opportunities of mouse models. Oncoimmunology (2012) 1:1584-93. doi: 10.4161/onci.22660

16. Kubo S, Takahashi HK, Takei M, Iwagaki H, Yoshino T, Tanaka N, et al. Eprostanoid (EP)2/EP4 receptor-dependent maturation of human monocytederived dendritic cells and induction of helper T2 polarization. J Pharmacol Exp Ther (2004) 309:1213-20. doi: 10.1124/jpet.103.062646

17. Harizi H, Grosset C, Gualde N. Prostaglandin E2 modulates dendritic cell function via EP2 and EP4 receptor subtypes. J Leukoc Biol (2003) 73:756-63. doi: $10.1189 /$ jlb. 1002483

18. van Helden SF, Krooshoop DJ, Broers KC, Raymakers RA, Figdor CG, van Leeuwen FN. A critical role for prostaglandin E2 in podosome dissolution and induction of high-speed migration during dendritic cell maturation. J Immunol (2006) 177:1567-74. doi: 10.4049/jimmunol.177.3.1567

19. Honda A, Sugimoto Y, Namba T, Watabe A, Irie A, Negishi M, et al. Cloning and expression of a cDNA for mouse prostaglandin E receptor EP2 subtype. J Biol Chem (1993) 268:7759-62. doi: 10.1016/S0021-9258(18)53022-2

20. Regan JW, Bailey TJ, Pepperl DJ, Pierce KL, Bogardus AM, Donello JE, et al. Cloning of a novel human prostaglandin receptor with characteristics of the pharmacologically defined EP2 subtype. Mol Pharmacol (1994) 46:213-20.

21. Leduc M, Breton B, Gales C, Le Gouill C, Bouvier M, Chemtob S, et al. Functional selectivity of natural and synthetic prostaglandin EP4 receptor ligands. J Pharmacol Exp Ther (2009) 331:297-307. doi: 10.1124/ jpet.109.156398

22. Fujino H, Regan JW. $\mathrm{EP}_{4}$ Prostanoid Receptor Coupling to a Pertussis ToxinSensitive Inhibitory G Protein. Mol Pharmacol (2006) 69:5-10. doi: 10.1124/ mol.105.017749

23. Desai S, April H, Nwaneshiudu C, Ashby B. Comparison of agonist-induced internalization of the human EP2 and EP4 prostaglandin receptors: role of the carboxyl terminus in EP4 receptor sequestration. Mol Pharmacol (2000) 58:1279-86. doi: 10.1124/mol.58.6.1279

24. Penn RB, Pascual RM, Kim YM, Mundell SJ, Krymskaya VP, Panettieri RAJr, et al. Arrestin specificity for $\mathrm{G}$ protein-coupled receptors in human airway smooth muscle. J Biol Chem (2001) 276:32648-56. doi: 10.1074/ jbc.M104143200

25. Desai S, Ashby B. Agonist-induced internalization and mitogen-activated protein kinase activation of the human prostaglandin EP4 receptor. FEBS Lett (2001) 501:156-60. doi: 10.1016/S0014-5793(01)02640-0

26. Mao Y, Sarhan D, Steven A, Seliger B, Kiessling R, Lundqvist A. Inhibition of tumor-derived prostaglandin-e2 blocks the induction of myeloid-derived suppressor cells and recovers natural killer cell activity. Clin Cancer Res (2014) 20:4096-106. doi: 10.1158/1078-0432.CCR-14-0635

27. Kiriyama M, Ushikubi F, Kobayashi T, Hirata M, Sugimoto Y, Narumiya S. Ligand binding specificities of the eight types and subtypes of the mouse prostanoid receptors expressed in Chinese hamster ovary cells. Br J Pharmacol (1997) 122:217-24. doi: 10.1038/sj.bjp.0701367

28. Wilson RJ, Giblin GM, Roomans S, Rhodes SA, Cartwright KA, Shield VJ, et al. GW627368X ((N-\{2-[4-(4,9-diethoxy-1-oxo-1,3-dihydro-2H-benzo[f] isoindol-2-yl)phenyl]acetyl $\}$ benzene sulphonamide): a novel, potent and selective prostanoid EP4 receptor antagonist. Br J Pharmacol (2006) 148:326-39. doi: 10.1038/sj.bjp.0706726

29. Woodward DF, Pepperl DJ, Burkey TH, Regan JW. 6-Isopropoxy-9oxoxanthene-2-carboxylic acid (AH 6809), a human EP2 receptor antagonist. Biochem Pharmacol (1995) 50:1731-3. doi: 10.1016/0006-2952 (95)02035-7

30. Luschnig-Schratl P, Sturm EM, Konya V, Philipose S, Marsche G, Frohlich E, et al. EP4 receptor stimulation down-regulates human eosinophil function. Cell Mol Life Sci (2011) 68:3573-87. doi: 10.1007/s00018-011-0642-5

31. Turcotte C, Zarini S, Jean S, Martin C, Murphy RC, Marsolais D, et al. The Endocannabinoid Metabolite Prostaglandin E2 (PGE2)-Glycerol Inhibits Human Neutrophil Functions: Involvement of Its Hydrolysis into PGE2 and EP Receptors. J Immunol (2017) 198:3255-63. doi: 10.4049/jimmunol.1601767

32. Thurner B, Roder C, Dieckmann D, Heuer M, Kruse M, Glaser A, et al. Generation of large numbers of fully mature and stable dendritic cells from leukapheresis products for clinical application. J Immunol Methods (1999) 223:1-15. doi: 10.1016/S0022-1759(98)00208-7

33. de Vries IJ, Eggert AA, Scharenborg NM, Vissers JL, Lesterhuis WJ, Boerman OC, et al. Phenotypical and functional characterization of clinical grade dendritic cells. J Immunother (2002) 25:429-38. doi: 10.1097/00002371-200209000-00007

34. Klarenbeek JB, Goedhart J, Hink MA, Gadella TW, Jalink K. A mTurquoisebased CAMP sensor for both FLIM and ratiometric read-out has improved dynamic range. PLoS One (2011) 6:e19170. doi: 10.1371/journal.pone.0019170

35. Gibson SK, Gilman AG. Gialpha and Gbeta subunits both define selectivity of G protein activation by alpha2-adrenergic receptors. Proc Natl Acad Sci USA (2006) 103:212-7. doi: 10.1073/pnas.0509763102

36. De Keijzer S, Meddens MB, Torensma R, Cambi A. The multiple faces of prostaglandin E2 G-protein coupled receptor signaling during the dendritic cell life cycle. Int J Mol Sci (2013) 14:6542-55. doi: 10.3390/ijms14046542

37. Hubbard NE, Lee S, Lim D, Erickson KL. Differential mRNA expression of prostaglandin receptor subtypes in macrophage activation. Prostaglandins Leukot Essent Fatty Acids (2001) 65:287-94. doi: 10.1054/plef.2001.0327

38. van Helden SF, van Leeuwen FN, Figdor CG. Human and murine model cell lines for dendritic cell biology evaluated. Immunol Lett (2008) 117:191-7. doi: 10.1016/j.imlet.2008.02.003

39. Bünemann M, Frank M, Lohse MJ. Gi protein activation in intact cells involves subunit rearrangement rather than dissociation. Proc Natl Acad Sci (2003) 100:16077-82. doi: 10.1073/pnas.2536719100

40. Wang N, Yan K, Rasenick MM. Tubulin binds specifically to the signaltransducing proteins, Gs alpha and Gi alpha 1. J Biol Chem (1990) 265:123942. doi: 10.1016/S0021-9258(19)40002-1 
41. Côté M, Payet MD, Gallo-Payet N. Association of $\alpha s$-Subunit of the Gs Protein with Microfilaments and Microtubules: Implication during Adrenocorticotropin Stimulation in Rat Adrenal Glomerulosa Cells1. Endocrinology (1997) 138:69-78. doi: 10.1210/endo.138.1.4860

42. Sarma T, Voyno-Yasenetskaya T, Hope TJ, Rasenick MM. Heterotrimeric Gproteins associate with microtubules during differentiation in PC12 pheochromocytoma cells. FASEB J (2003) 17:848-59. doi: 10.1096/fj.02-0730com

43. Scandella E, Men Y, Gillessen S, Forster R, Groettrup M. Prostaglandin E2 is a key factor for CCR7 surface expression and migration of monocyte-derived dendritic cells. Blood (2002) 100:1354-61. doi: 10.1182/blood-2001-11-0017

44. Kabashima K, Sakata D, Nagamachi M, Miyachi Y, Inaba K, Narumiya S. Prostaglandin E2-EP4 signaling initiates skin immune responses by promoting migration and maturation of Langerhans cells. Nat Med (2003) 9:744-9. doi: $10.1038 / \mathrm{nm} 872$

45. Flórez-Grau G, Cabezón R, Borgman KJE, España C, Lozano JJ, Garcia-Parajo $\mathrm{MF}$, et al. Up-regulation of EP2 and EP3 receptors in human tolerogenic dendritic cells boosts the immunosuppressive activity of PGE2. J Leukoc Biol (2017) 102:881-95. doi: 10.1189/jlb.2A1216-526R

46. Poloso NJ, Urquhart P, Nicolaou A, Wang J, Woodward DF. PGE(2) differentially regulates monocyte-derived dendritic cell cytokine responses depending on receptor usage (EP(2)/EP(4)). Mol Immunol (2013) 54:284-95. doi: 10.1016/j.molimm.2012.12.010

47. Yao C, Sakata D, Esaki Y, Li Y, Matsuoka T, Kuroiwa K, et al. Prostaglandin E2-EP4 signaling promotes immune inflammation through TH1 cell differentiation and TH17 cell expansion. Nat Med (2009) 15:633-40. doi: 10.1038/nm.1968

48. Fujino H, West KA, Regan JW. Phosphorylation of glycogen synthase kinase3 and stimulation of T-cell factor signaling following activation of EP2 and EP4 prostanoid receptors by prostaglandin E-2. J Biol Chem (2002) 277:26149. doi: 10.1074/jbc.M109440200

49. Fujino H, Xu W, Regan JW. Prostaglandin E2 induced functional expression of early growth response factor-1 by EP4, but not EP2, prostanoid receptors via the phosphatidylinositol 3-kinase and extracellular signal-regulated kinases. J Biol Chem (2003) 278:12151-6. doi: 10.1074/jbc.M212665200

50. Fujino H, Salvi S, Regan JW. Differential regulation of phosphorylation of the cAMP response element-binding protein after activation of EP2 and EP4 prostanoid receptors by prostaglandin E2. Mol Pharmacol (2005) 68:251-9. doi: $10.1124 / \mathrm{mol} .105 .011833$

51. Hamdan FF, Rochdi MD, Breton B, Fessart D, Michaud DE, Charest PG, et al. Unraveling G Protein-coupled Receptor Endocytosis Pathways Using Realtime Monitoring of Agonist-promoted Interaction between $\beta$-Arrestins and AP-2. J Biol Chem (2007) 282:29089-100. doi: 10.1074/jbc.M700577200

52. Bondar A, Lazar J. G protein Gil exhibits basal coupling but not preassembly with G protein-coupled receptors. J Biol Chem (2017) 292:9690-8. doi: 10.1074/jbc.M116.768127

53. Sungkaworn T, Jobin M-L, Burnecki K, Weron A, Lohse MJ, Calebiro D. Single-molecule imaging reveals receptor-G protein interactions at cell surface hot spots. Nature (2017) 550:543-7. doi: 10.1038/nature24264

54. Abramovitz M, Adam M, Boie Y, Carriere M, Denis D, Godbout C, et al. The utilization of recombinant prostanoid receptors to determine the affinities and selectivities of prostaglandins and related analogs. Biochim Biophys Acta (2000) 1483:285-93. doi: 10.1016/S1388-1981(99)00164-X
55. Sleno R, Hebert TE. The Dynamics of GPCR Oligomerization and Their Functional Consequences. Int Rev Cell Mol Biol (2018) 338:141-71. doi: 10.1016/bs.ircmb.2018.02.005

56. Head BP, Patel HH, Roth DM, Murray F, Swaney JS, Niesman IR, et al. Microtubules and actin microfilaments regulate lipid raft/caveolae localization of adenylyl cyclase signaling components. J Biol Chem (2006) 281:26391-9. doi: 10.1074/jbc.M602577200

57. Pontier SM, Percherancier Y, Galandrin S, Breit A, Galés C, Bouvier M. Cholesterol-dependent Separation of the 32 -Adrenergic Receptor from Its Partners Determines Signaling Efficacy: INSIGHT INTO NANOSCALE ORGANIZATION OF SIGNAL TRANSDUCTION. J Biol Chem (2008) 283:24659-72. doi: 10.1074/jbc.M800778200

58. Allen JA, Yu JZ, Dave RH, Bhatnagar A, Roth BL, Rasenick MM. Caveolin-1 and Lipid Microdomains Regulate Gs Trafficking and Attenuate Gs/Adenylyl Cyclase Signaling. Mol Pharmacol (2009) 76:1082-93. doi: 10.1124/ mol.109.060160

59. Czysz AH, Schappi JM, Rasenick MM. Lateral Diffusion of Gos in the Plasma Membrane Is Decreased after Chronic but not Acute Antidepressant Treatment: Role of Lipid Raft and Non-Raft Membrane Microdomains. Neuropsychopharmacology (2015) 40:766-73. doi: 10.1038/npp.2014.256

60. Agarwal SR, Yang P-C, Rice M, Singer CA, Nikolaev VO, Lohse MJ, et al. Role of Membrane Microdomains in Compartmentation of cAMP Signaling. PloS One (2014) 9:e95835. doi: 10.1371/journal.pone.0095835

61. Bogard AS, Adris P, Ostrom RS. Adenylyl Cyclase 2 Selectively Couples to E Prostanoid Type 2 Receptors, Whereas Adenylyl Cyclase 3 Is Not ReceptorRegulated in Airway Smooth Muscle. J Pharmacol Exp Ther (2012) 342:58695. doi: 10.1124/jpet.112.193425

62. Ma X, Holt D, Kundu N, Reader J, Goloubeva O, Take Y, et al. (PGE) receptor EP4 antagonist protects natural killer cells from PGE-mediated immunosuppression and inhibits breast cancer metastasis. Oncoimmunology (2013) 2:e22647. doi: 10.4161/onci.22647

63. Majumder M, Xin X, Liu L, Girish GV, Lala PK. Prostaglandin E2 receptor EP4 as the common target on cancer cells and macrophages to abolish angiogenesis, lymphangiogenesis, metastasis, and stem-like cell functions. Cancer Sci (2014) 105:1142-51. doi: 10.1111/cas.12475

64. Albu DI, Wang Z, Huang KC, Wu J, Twine N, Leacu S, et al. EP4 Antagonism by E7046 diminishes Myeloid immunosuppression and synergizes with Tregreducing IL-2-Diphtheria toxin fusion protein in restoring anti-tumor immunity. Oncoimmunology (2017) 6:e1338239. doi: 10.1080/2162402X.2017. 1338239

Conflict of Interest: The authors declare that the research was conducted in the absence of any commercial or financial relationships that could be construed as a potential conflict of interest.

Copyright (c) 2021 Vleeshouwers, van den Dries, de Keijzer, Joosten, Lidke and Cambi. This is an open-access article distributed under the terms of the Creative Commons Attribution License (CC BY). The use, distribution or reproduction in other forums is permitted, provided the original author(s) and the copyright owner(s) are credited and that the original publication in this journal is cited, in accordance with accepted academic practice. No use, distribution or reproduction is permitted which does not comply with these terms. 